\title{
Testing the Lunar Surface
}

\section{from our Astronomy Correspondent}

When astronaut Neil Armstrong sets foot on the Moon next week (and planning has reached such a pitch that NASA engineers have decided that Armstrong's left foot should be the first to make contact), the United States will have spent a large part of its $\$ 36 \cdot 4$ thousand million space budget since 1959 on making sure that the lunar surface is strong enough to bear his weight. For in the early 1950s, scientists interested in the Moon, then a parochial backwater off the mainstream of astronomy, were hotly debating whether a spacecraft landing on the Moon would flounder hopelessly in an intractable sea of dust. Chief proponent of the dust hypothesis was Professor T. Gold, in those days at the Royal Greenwich Observatory, who considered that a dust layer might explain the appearance of some of the craters (for example, Mon. Not. R. Astron. Soc., 155, $585 ; 1955)$. Even as late as 1965, Professor Gold was able to say of the Ranger spacecraft which provided close-ups of the Moon: "they cannot tell us whether it is material we can walk on, or something we would wallow in" (The Nature of the Lunar Surface, Proc. 1965 $I A U-N A S A$ Symp., 107). But although many astronomers doubted that the lunar surface was as soft as Gold suggested, NASA had to make sure, and between 1966 and 1968, seven Surveyor softlanders were launched which among other things tested the surface strength. Fortunately for the Apollo project, none of them disappeared in a layer of dust, and the last of the results which the five successful Surveyors radioed back are now being analysed.

Yet, leaving out the measurements on the strength of the lunar surface, the Surveyor data resemble those from the Rangers in the sense that data are being used by opposing sides in a controversy, this time about the mineralogical make-up of the surface layers. The Ranger photographs, on the other hand, were expected to settle the question whether the lunar surface was shaped primarily by meteoritic impact or by volcanic activity. But after three successful Ranger shots out of seven, the question is still open. The chances are that the long-awaited samples which Armstrong and Aldrin will bring back will not provide an unambiguous potted history of the Moon either, and selenologists will have to piece together the results from several expeditions before a coherent picture emerges. This is particularly so because the first samples will be collected from within about 100 feet of the Junar module, and may well be affected by the rocket exhaust.

What will the surface be like? An armoury of instruments carried by the Surveyors has prepared the astronauts for what to expect. The chief items were a television camera to photograph the Iunar terrain, and to see how far the footpads had sunk into the surface, a retractable scoop to test the consistency of the material, and a capsule of curium-242 as a source of alpha particles to probe the chemical composition of the surface. As a bonus, some of the Surveyors had colour filters which could be switched in front of the camera lens so that colour pictures of the surface could be built up, showing the grey-brown material which the Apollo 8 and 10 astronauts described. A summary of the Surveyor results has been published by Leonard D. Jaffe, manager of Surveyor data analysis at the Jet
Propulsion Laboratory of Caltech (Science, 164, 775; 1969). By looking at the depressions produced by the footpads, and by imprints on the surface made by the retractable scoop under instructions from the Earth, the static bearing strength is estimated as $0 \cdot 1$ newton $\mathrm{cm}^{2}$ at a depth of $1 \mathrm{~mm}$, and 5 newtons $\mathrm{cm}^{2}$ at a depth of $5 \mathrm{~cm}$. The television photographs show the surface as disappointingly like terrestrial soil - a matrix of bulk density $1.5 \mathrm{~g} \mathrm{~cm}^{-3}$ made up of slightly cohesive particles generally less than $1 \mathrm{~mm}$ across, but with larger clods of particles and some more solid-looking boulders intermixed. Estimates of the porosity are between 40 and 50 per cent. Because the soil took an impression of a pattern of ridges only 50-70 microns deep on the bottom of a footpad, an appreciable component of the soil must be finer than 60 microns, and one estimate of the peak of the mass distribution is 10 microns. From the appearance of craters photographed by Surveyor, the granular matrix extends to a depth which varies between 1 and 20 metres. At greater depths the material seems to be stronger, but may still be a matrix of small particles-some of the rocks ejected from the prominent crater Tycho look porous, for example. The cohesion of the surface material was tested using the spacecraft engines to disturb the surface, and with the retractable scoop. Trenches dug by the scoop, for example, to depths up to $18 \mathrm{~cm}$, had sharp vertical walls which did not collapse. And Jaffe reports that in general the material did not stick to the spacecraft, except when rubbed against spacecraft surfaces by the scoop.

But the important clues to the composition of the surface material come from the curium-242 and from magnets clipped to the footpads and photographed with the television camera. By measuring the energy spectrum of the alpha particles from the curium source which had been reflected back from the top 25 microns of the surface, a rough chemical analysis was produced. Three Surveyors carried this facility, and the dogma of the Surveyor team is that in each case the composition corresponds to basalt. Yet Dr Gilvarry of the RAND Corporation claims that the chemical analyses for the maria regions at least also fit the compositions of shales and sandstones, a possibility which the Surveyor team seems to have ignored, and that shale gives a better fit than basalt. Dr Gilvarry therefore argues that the Surveyor results agree with his hypothesis that the maria are dried up oceans, and that their dark coloration is due to decayed organic matter (Nature, 218, 336; 1968). On the other hand, Dr J. Negus de Wys of JPL reports that the amount of material adhering to the magnet fixed on a footpad of Surveyor 5 was consistent with a landing in powdered basalt with no addition of powdered iron ( $J$. Geophys. Res., 73, 7193; 1968). This is one question at least which next week's landing should solve.

Of the five successful Surveyors, four investigated possible landing sites in mare areas within $3^{\circ}$ of the lunar equator while as a bonus the fifth, Surveyor 7, was landed on the flank of the crater Tycho in the southern hemisphere highlands. But the results which most concern Armstrong and Aldrin are from Surveyor 5 which was aimed at the corner of Mare Tranquillitatis where next week's landing will be. The Surveyor 5 
results, summarized in a series of papers in $J$. Geophys. Res. (73, 7161; 1968), provide scant information about the roughness of the area because the spacecraft landed in a small crater about $12 \mathrm{~m}$ across. But $\mathrm{Mr}$ D. E. Gault, who heads the planetology branch of the
Ames Research Center, is reported as saying that Surveyors 1 and 3 in Oceanus Procellarum showed the lunar surface to be more strewn with debris than expected from the Ranger photographs. Clearly, Noil Armstrong is going to need all his skill as a pilot.

\section{Brazil}

Although there have been no further dismissals of Brazilian academics since the publication of two lists of people on April 21 and April 30, there has so far been no relaxation of the government's pressure on the universities. The result is that many academics are moving abroad - the government of Brazil appears to have placed no obstacles in the way of doing soand it is known, for example, that five of the twentythree sacked from São Paulo University on April 23, and "deprived of their political rights" for ten years, have since left the country.

A statement of some of the current problems in Brazilian universities, prepared by a group of science professors there, has now reached the Nature office. One immediate consequence of the sacking of the sixtythree professors in April has been to unsettle those unaffected by the decree, with the result that many of those still holding positions in Brazil hope soon to move elsewhere. The view here is that there seems no immediate prospect that the statutes which have made the repression of the universities possible will be amended in the near future although it does seem possible that external pressure may soften the rigour with which the statutes are applied. In this sense, the visit of Governor Rockefeller to Brazil two weeks ago is reckoned by some to have been helpful in limiting sackings from the universities.

A more serious problem than the sacking of university teachers may be the effect of the legislation on students. It is known that a number of students were expelled from the University of Rio de Janeiro on June 21, under the provisions of Decree 477. The statement by the group of Brazilian academics points out that although university teachers may often be able to move abroad, students who are expelled from universities for political reasons will be unable to complete their training. One of the suggestions put forward is that there should be a scheme for providing students cxpelled from Brazilian universities with scholarships to enable them to complete their courses elsewhere, but even if there were funds for handling such a problem, the lack of information about the dismissal of students is an impediment to effective international remedial action.

The root of the legislation under which the government of Brazil has moved against the universities is Institutional Act No. 5 of December 13, 1968. This allows the president of the republic to dismiss the congress and govern by decree. This same legislation introduced a new penalty of the "suspension of political rights" and a number of new offences. One of the articles of this act which affects universities directly is the definition as subversive propaganda of the incitement to action of "persons in their working place or in schools" as well as the holding of "assemblies, public meetings and public demonstrations".

The mechanism for dealing with university discipline is defined by a decree (No. 477) of February 26, 1969. This lays down that it is an offence to paralyse the activities of a school, to plot against educational institutions of all kinds, to organize or participate in picketings and parades, to distribute or even to have subversive material, to kidnap the director of an institution or his teaching staff and to use the property of a school for subversive or immoral purposes. The decree lays down that faculty members convicted under this decree will be dismissed and prevented from teaching for five years. For students, the penalty is expulsion with a restriction on attending another institution for three years. Domestic scholarship holders are deprived of their scholarships and foreign scholarship holders are required to leave the country.

Responsibility for the administration of university discipline rests with the director of the institution concerned, who can be required to take action by the Ministry of Education and Culture or by "any other authority or person". Persons convicted under the provisions of the decree are punished automatically. If the director of an institution or the deputy appointed for the purpose fails to find an alleged transgressor guilty, the case must automatically be appealed to the Ministry of Education.

As yet, there is very little numerical information about the application of these decrees, although it is known that students have been expelled from Brasilia and Rio de Janeiro. One of the difficulties is that the confidential instructions on press censorship which came into force on June 10 this year specifically forbid the publication of news about "comments, interviews, statements of any person concerning student unions dissolved by the government or concerning extracurricular political activities, protests, manifestations, conflicts with teachers or with authorities". Among the academics recently sacked are three people who had returned to Brazil at the end of last year, at a time when the government seemed to be anxious to bring people back. These include Sebastiao B. Henriques and his wife Olga, both biologists, who had just returned from the Soviet Union, and L. H. Pereira da Silva who had spent the past academic year at the Institut Pasteur in Paris.

Further information about academic posts which may be suitable for some of those affected by the decrees in Brazil may be sent to the Nature office. There follows a more complete list than that published on Junc 7 of the scientists affected.

Professors M. Schemberg, J. Leite Lopes, M. L. M. Leite Lopes, J. Tiomno, E. F. Pessoa, S. B. Henriques, O. B. Henriques, L. H. Pereira da Silva, J. C. Cardoso, A. A. L. Zamith, F. Fernandes, Isaias Raw, F. H. Cardoso, M. L. Bastos, O. Ianni, P. Singer, P. C. Padis, M. Y. L. Linhares, M. S. P. de Vasconcelos, A. Carvalho da Silva, H. L. de Oliveira, J. B. V. N. Artigas, Q. Campofiorito. 